\title{
PESQUISA
}

\section{CIÊNCIA E PSICOLOGIA: UMA COMPREENSÃO À PARTIR DAS REPRESENTAÇÕES SOCIAIS}

\author{
Gislene Farias de Oliveira(1) \\ Patrícia Nunes Fonseca(2)
}

\section{RESUMO}

As Representações Sociais (RS) acerca da Ciência e da Psicologia, sua importância e as percepções acerca do papel do psicólogo na sociedade, entre estudantes de universidades públicas e privadas de João Pessoa-PB, constituíram o foco de interesse deste estudo. Nosso objetivo foi compreender de que forma a concepção que possuem de ciência influencia a percepção da Psicologia, uma vez que a primeira encontra-se implicada na vida cotidiana dos atores sociais envolvidos. A amostra constituiu-se de 66 acadêmicos e o instrumento utilizado foi a entrevista semi-dirigida. Através da análise de conteúdo, observou-se que as representações sociais dos estudantes fizeram emergir tanto Concepções de Ciência como estudo e como conhecimento, mais relacionadas com uma concepção racionalista, como também, a ciência como algo que provém de uma comprovação empírica, desvendada através de um método, nestes casos, uma concepção empirista, onde a ciência é concebida como uma interpretação dos fatos baseada em experimentos. Emergiu ainda uma percepção de ciência como investigação ou algo para explicar o desconhecido. Neste caso uma concepção construtivista, onde a ciência não objetivaria apresentar uma verdade absoluta, mas uma verdade aproximada, que pode ser corrigida, modificada ou abandonada por outra mais adequada.

Palavras-Chave: Representações Sociais, Ciência, Psicologia.

(1) Psicóloga, professora da Universidade Regional do Cariri e da Universidade Federal do Ceará. Doutoranda em Psicologia Social pela Universidade Federal da Paraíba.

(2) Psicóloga, professora da Universidade Federal da Paraíba, doutoranda em Psicologia Social pela Universidade Federal da Paraíba 
Poderia se pensar que a ciência, algo de sentido eminentemente lógico, que caracteriza a academia, excluiria a formação de Representações Sociais (RS), uma vez que esta ocorre em sentido oposto ao da ciência. Existem diversos objetos sociais que interessam a determinado grupo acadêmico, como a arte, a política, o esporte, o papel da universidade na sociedade, e existem também objetos sociais que parecem alheios aos interesses de determinados grupos acadêmicos, como o comércio ou a psicologia.

Assim, acreditamos ser interessante estudar as RS no grupo dos acadêmicos. Este, de fato, não é apenas um agrupamento de alunos, mas um agrupamento de pessoas, num certo tempo e lugar, envolvidas na tarefa científica e em relações interpessoais e institucionais que se complementam.

Partimos da hipótese de que o conceito de ciência poderia influenciar a concepção que os alunos têm de Psicologia. O que por sua vez, motivaria o grau de importância atribuída à esta área de conhecimento.

A definição de ciência não está caracterizada por um corpus único, mas descreve um conjunto de saberes e conhecimentos que se estruturam sistematicamente e que são obtidos mediante observação e inferência racional dos acontecimentos (RODRÍGUEZ, 2005).

Ao longo da história, pode-se perceber um número cada vez maior de explicações e descrições mais detalhadas, mais qualificadas e mais abundantes sobre o mundo e o que nele acontece.

Ciência é o processo pelo qual o homem se relaciona com os fenômenos universais que se sujeitam à regra científica fundamental (MESQUITA FILHO, 2005). Segundo Chauí (2000), historicamente, as principais concepções de ciência em termos de cientificidade são: a concepção racionalista, com um modo de pensar baseado na objetividade matemática; a concepção empirista, baseada nos moldes do pensamento da medicina grega e da história natural do século XVII; e a concepção construtivista, mais baseada na razão.

A concepção racionalista se estende dos gregos até o final do século XVII e afirma que a ciência é um conhecimento racional dedutivo e demonstrativo como a matemática, portanto, capaz de provar a verdade necessária e universal de seus enunciados e resultados, sem deixar qualquer dúvida possível. Portanto, uma ciência seria uma unidade sistemática de axiomas, postulados e definições, que determinariam a natureza e as propriedades de seus objetos, de forma que seria possível provar as relações de causalidade de um objeto investigado.

A concepção empirista vai da medicina grega e Aristóteles até o final do século XIX e afirma que a ciência é uma interpretação dos fatos baseada em observações e experimentos. 
Tais experimentos permitiriam uma definição mais realista do objeto, das suas propriedades e das suas leis de funcionamento. Dessa forma, uma teoria científica resultaria das observações e dos experimentos. Observe-se que nesta concepção há necessidade de um maior rigor nos procedimentos experimentais, uma vez que deles dependeria a formulação da teoria acerca do objeto investigado.

A concepção construtivista foi iniciada no século passado e considera a ciência uma construção de modelos explicativos para a realidade e não uma representação da própria realidade. Não espera, portanto, apresentar uma verdade absoluta a partir das observações e experimentos e sim uma verdade aproximada, que pode ser corrigida, modificada, abandonada por outra mais adequada (CHAUI, 2000).

Segundo a autora, são três as exigências de seu ideal de cientificidade: A coerência, isto é, isenção de contradições entre os princípios norteadores da teoria; que os modelos dos objetos (ou as estruturas dos fenômenos) se constituam com base na observação ou na experimentação; e que os resultados alterem os modelos constituídos.

A concepção construtivista, assim como a racionalista, exige que o método lhe permita e lhe garanta estabelecer axiomas, postulados, definições e deduções sobre o objeto científico. Da mesma forma que a concepção empirista, a construtivista exige que a experimentação guie e modifique axiomas, postulados, definições e demonstrações. No entanto, os teóricos construtivistas não esperam que seu trabalho apresente a realidade em si mesma, mas ofereça estruturas e modelos de funcionamento da realidade, explicando os fenômenos observados.

A passagem do racionalismo e empirismo ao construtivismo, isto é, de um ideal de cientificidade baseado na idéia de que a ciência é uma representação da realidade tal como ela é em si mesma, a um ideal de cientificidade baseado na idéia de que o objeto científico é um modelo construído e não uma representação do real, uma aproximação sobre o modo de funcionamento da realidade, mas não o conhecimento absoluto dela, representou uma primeira grande mudança científica. A segunda mudança refere-se à passagem da ciência antiga, mais teórica e qualitativa, à ciência moderna, mais tecnológica e quantitativa.

Durante certo tempo, julgou-se que a ciência evolui e progride. Evolução e progresso são duas idéias muito recentes - datam dos séculos XVIII e XIX -, mas muito aceitas pelas pessoas. As noções de evolução e de progresso partem da suposição de que o tempo é uma linha reta contínua e homogênea. O tempo seria uma sucessão contínua de instantes, momentos, fases, períodos, épocas, que iriam se somando uns aos outros, acumulando-se de 
tal modo que o que acontece depois é o resultado melhorado do que aconteceu antes (BUENO, 1995).

Evoluir significa: tornar-se superior e melhor do que se era antes. Progredir significa: ir num rumo cada vez melhor na direção de uma finalidade superior. Evolução e progresso também supõem o tempo como uma série linear de momentos ligados por relações de causa e efeito, em que o passado é causa e o presente, efeito, vindo a tornar-se causa do futuro. Vemos essa idéia aparecer quando, por exemplo, os manuais de História apresentam as “influências” que um acontecimento anterior teria tido sobre um outro, posterior. Evolução e progresso pressupõem: continuidade temporal, acumulação causal dos acontecimentos, superioridade do futuro e do presente com relação ao passado, existência de uma finalidade a ser alcançada. Supunha-se que as mudanças científicas indicavam evolução ou progresso dos conhecimentos humanos (BUENO, 1995).

A Filosofia das Ciências, estudando as mudanças científicas, impôs um desmentido às idéias de evolução e progresso. Isso não quer dizer que a Filosofia das Ciências viesse a falar em atraso e regressão científica. Segundo Khun (1976), um campo científico é criado quando métodos, tecnologias, formas de observação e experimentação, conceitos e demonstrações formam um todo sistemático, uma teoria que permite o conhecimento de inúmeros fenômenos. A teoria se torna um modelo de conhecimento ou um paradigma científico. Em tempos normais, um cientista, diante de um fato ou de um fenômeno ainda não estudado, usa o modelo ou o paradigma científico existente. Uma revolução científica acontece quando o cientista descobre que os paradigmas disponíveis não conseguem explicar um fenômeno ou um fato novo, sendo necessário produzir um outro paradigma, até então inexistente e cuja necessidade não era sentida pelos investigadores.

A ciência, portanto, parece não caminhar numa via linear contínua e progressiva, mas por saltos ou revoluções. A ciência contemporânea apresenta características construtivistas quando julga que fatos e fenômenos novos podem exigir a elaboração de novos métodos, novas tecnologias e novas teorias.

Alguns filósofos da ciência, entre os quais Karl Popper (1963), afirmaram que a reelaboração científica decorre do fato de ter havido uma mudança no conceito filosóficocientífico da verdade. Esta foi considerada durante muitos séculos como a correspondência exata entre uma idéia ou um conceito e a realidade. Popper afirma que as mudanças 
científicas são uma conseqüência da concepção da verdade como coerência teórica, e propõe que uma teoria científica seja avaliada pela possibilidade de ser falsa ou falsificada (MAGEE, 1979).

Uma teoria científica é boa, quanto mais estiver aberta a fatos novos que possam tornar falsos os princípios e os conceitos em que se baseava. Assim, o valor de uma teoria não se mede por sua verdade, mas pela possibilidade de ser falsa. A falseabilidade seria o critério de avaliação das teorias científicas e garantiria a idéia de progresso científico, pois é a mesma teoria que vai sendo corrigida por fatos novos que a falsificam (POPPER, 1993).

A maioria dos filósofos da ciência, entre os quais Khun (1976), demonstrou o absurdo da posição de Popper (1963). De fato, dizem eles, jamais houve um único caso em que uma teoria pudesse ser falsificada por fatos científicos. Jamais houve um único caso em que um fato novo garantisse a coerência de uma teoria, bastando impor a ela mudanças totais.

Cada vez que fatos provocaram verdadeiras e grandes mudanças teóricas, essas mudanças não foram feitas no sentido de "melhorar” ou “aprimorar” uma teoria existente, mas no sentido de abandoná-la por uma outra. O papel do fato científico não é o de falsear ou falsificar uma teoria, mas de provocar o surgimento de uma nova teoria verdadeira. É o verdadeiro e não o falso que guia o cientista, seja a verdade entendida como correspondência entre idéia e coisa, seja entendida como coerência interna das idéias.

A cada nova descoberta científica, são geradas novas idéias existindo aí uma possibilidade de transformação das representações sociais.

Segundo Moscovici (1984, p.251), é a “Representação social compreendida como a elaboração de um objeto social pela comunidade, com o propósito de conduzir-se e comunicar-se”, portanto um instrumento de agregação e de socialização do saber de um grupo social.

A teoria das representações sociais tem um papel fundamental na dinâmica das relações sociais e nas concepções de mundo que os sujeitos elaboram, que responderia a quatro funções essenciais. Dentre elas, a função identitária, que "definem a identidade $e$ permitem a proteção da especificidade dos grupos”, tendo “um papel importante no controle social exercido pela coletividade sobre cada um de seus membros e, em especial, nos processos de socialização" (ABRIC,1998, p.29). Ainda segundo o autor, as representações, 
enquanto função de orientação, guiam os comportamento e as práticas, definindo regras sobre o que é lícito ou aceitável, conforme a expectativa do grupo - que unem socialmente os seus membros. Observando que o avanço da tecnologia da comunicação e a globalização, facilitam o emergir de novos valores.

O Objetivo deste estudo foi o de identificar e analisar as representações sociais acerca de Ciência e da Psicologia enquanto ciência, elaboradas por acadêmicos de universidades públicas e privadas de João Pessoa.

Fizeram parte desta pesquisa 66 sujeitos adultos todos acadêmicos de Universidades públicas e particulares do Município de João Pessoa - PB, com faixa etária entre 18 e 29 anos. Para a coleta dos dados utilizou-se Entrevitas Semi-dirigidas que constaram dos seguintes questionamentos: O que é ciência para você?; O que é psicologia para você?; Qual a importância da Psicologia, do seu ponto de vista?; No seu modo de pensar, qual o papel do psicólogo na sociedade?

As informações foram colhidas diretamente dos sujeitos, a partir dos seus relatos, através de formulário construído para o propósito da pesquisa.

A análise final foi feita através de um confronto entre as respostas elucidadas pelos sujeitos nas entrevistas, visando se chegar a uma compreensão das concepções acerca da ciência e da psicologia, com base nos estudos das representações sociais. A escolha da teoria se justifica, tendo em vista que,

A utilização da teoria das representações sociais, no diagnóstico psicossocial é bastante útil, à medida que se lida com um marco conceitual que envolve, tanto o nível intrapessoal de análise, como o interpessoal e o grupo; desta forma, é possível partir das representações sociais, para um exame das cognições no nível grupal, que permitem ao pesquisador, a apreensão dos aspectos compartilhados de uma representação (COUTINHO, 2001, p.65).

A análise de conteúdo é, segundo Vala (1986), uma das técnicas mais comuns em pesquisas empíricas realizadas em diferentes ciências humanas e sociais. No que tange à análise temática, enfatiza-se a análise de ocorrências, objetivando revelar a atenção dada pelos sujeitos entrevistados ao discurso, conferindo-lhe diferentes conteúdos inventariados. Observa-se que esse tipo de análise permite inferências sobre a organização do sistema de pensamento dos sujeitos, produtores do discurso, sobre a penitência e suas práticas. 
Inicialmente, dentro de uma seqüência cronológica, o referido autor pontua a definição de Berelson (1952) e a de Krippendorff (1980). Entre outros estudiosos da análise de conteúdo, situa-se Bardin (1991). Berelson (1952) afirma ser a análise de conteúdo uma técnica de investigação que permite a descrição objetiva, sistemática e quantitativa do conteúdo manifesto da comunicação. Krippendorff (1980) a define como uma técnica de investigação que permite fazer inferências válidas e reaplicáveis, dos dados, no seu contexto.

Seguindo esses pensamentos é importante destacar a definição de Bardin (1991), que afirma ser a análise de conteúdo:

(...) um conjunto de técnicas de análise das comunicações visando obter, por procedimentos sistemáticos e objetivos de descrição do conteúdo das mensagens, indicadores (quantitativos ou não) que permitem a inferência de conhecimentos relativos às condições de produção/recepção (variáveis inferidas) destas mensagens... (p. 42).

Vala (1986) comenta os aspectos conceituais da análise de conteúdo abordada por diferentes autores, afirmando que:

(...) o caráter objetivo e sistemático da análise de conteúdo referido por Berelson e Cartwright e as condições de validade e replicabilidade expressa por Krippendorff enquanto técnica de pesquisa, a análise de conteúdo exige a maior explicitação de todos os procedimentos utilizados (...) (p. 103).

Assim sendo, esta técnica, enquanto analisa as condições de produção do discurso, efetua inferências sobre as mensagens inventariadas e sistematizadas, articulando o discurso com o contexto de produção.

Baseando-se nesse contexto teórico-metodológico, utilizou-se a análise de conteúdo, tomando-se por base os objetivos propostos nesse estudo, subsidiados na teoria das Representações Sociais.

O corpus foi constituído por 66 entrevistas de questões abertas. Após a leitura flutuante do corpus, foram definidas as categorias emergentes (empíricas) e codificadas. Para 
a escolha das unidades de análise, esta técnica baseou-se na abordagem de Vala (1986). Em sua abordagem, geralmente, só existem dois tipos de unidades: formais e semânticas. As unidades formais incluem palavras, frases, um personagem ou a intervenção do locutor; as unidades semânticas compreendem o tema ou a unidade de informação.

Neste estudo, optou-se pelas unidades de contexto, que, segundo definições do referido autor, são compreendidas pelos segmentos mais largos de conteúdo.

Após a decomposição do corpus e a codificação dos temas agrupou-se o material em subcategorias e categorias.

O corpus foi agrupado em cinco conjuntos de categorias, no caso das Representações Sociais de Ciência e de Psicologia enquanto Ciência:

\section{Resultados}

Quadro 1. DISTRIBUIÇÃO DAS CATEGORIAS E SUBCATEGORIAS

\begin{tabular}{|c|c|c|}
\hline Categorias & Subcategorias & $\%$ \\
\hline $\begin{array}{l}\text { CATEGORIA } 1 \text { - (CCI) } \\
\text { Concepção de Ciência }\end{array}$ & $\begin{array}{ll}\text { - } & \text { Estudo } \\
\text { - } & \text { Conhecimento } \\
\text { - } & \text { Comprovação empírica } \\
\text { - } & \text { Método/Metodologia } \\
\text { - Investigação } \\
\text { - Explicar }\end{array}$ & $\begin{array}{r}28,2 \\
26,5 \\
15,4 \\
13,7 \\
10,2 \\
6,0\end{array}$ \\
\hline$\frac{\text { CATEGORIA } 2 \text { - (PPS) }}{\text { Percepção da Psicologia }}$ & 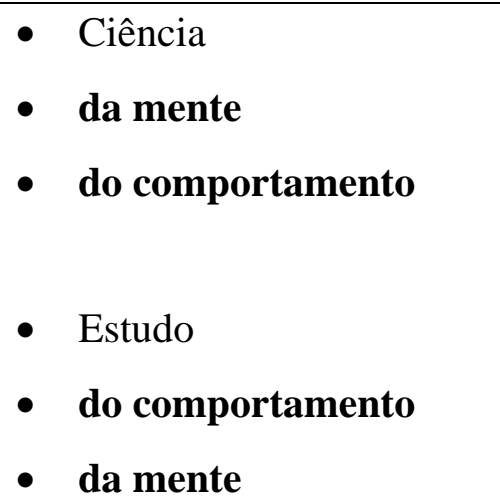 & $\begin{array}{r}69,3 \\
42,0 \\
27,3 \\
\\
30,7 \\
15,9 \\
14,8\end{array}$ \\
\hline
\end{tabular}




\begin{tabular}{|c|c|c|}
\hline CATEGORIA 3 - (IPS) & $\begin{array}{l}\text { - } \text { Ajudar } \\
\text { - Estudar }\end{array}$ & $\begin{array}{l}37,6 \\
24,0\end{array}$ \\
\hline Importância da Psicologia & $\begin{array}{ll}\text { - } & \text { Compreender } \\
\text { - } & \text { Auto-conhecimento } \\
\text { - } & \text { Resolver } \\
\text { - } & \text { Tratar }\end{array}$ & $\begin{array}{r}18,7 \\
9,4 \\
6,2 \\
4,1\end{array}$ \\
\hline $\begin{array}{l}\text { CATEGORIA } 4 \text { - (IPP) } \\
\text { Imagem do Papel do Psicólogo }\end{array}$ & $\begin{array}{ll}\text { - } & \text { Ajudar } \\
\text { - } & \text { Melhorar } \\
& \text { relacionamentos } \\
\text { - } & \text { Melhorar bem-estar } \\
\text { - } & \text { Compreender } \\
\text { - } & \text { Estudar } \\
\text { - } & \text { Solucionar conflitos }\end{array}$ & $\begin{array}{r}41,3 \\
22,3 \\
16,4 \\
8,2 \\
5,9 \\
5,9\end{array}$ \\
\hline
\end{tabular}

A CATEGORIA 1 - (CCI), refere-se à Concepção sobre Ciência, evocadas pelos sujeitos, onde sobressaíram-se seis subcategorias: Estudo: estudo aprofundado...; estudo de uma determinada área...; algo que se estuda...; existe para estudar...”; estudo científico...; estudos sobre determinado assunto...; estudo dos fenômenos...; estudo das condições...; estuda a vida... de uma maneira geral...; estudo de tudo...; estudo de vários elementos...; estudo de uma determinada coisa...; estudo da vida material...; estudo...; estudo de vários fenômenos...; estuda os fatos...; é um estudo...; estudo geral do meio...; estudo do mundo...; estudo de determinada área...; algo que estuda as coisas...; estudo dos seres vivos...; estudo através...; estudo de algumas coisas...; estudo que...; estudar, pesquisar...; objeto de estudo...;, Conhecimento: conhecimento sistemático...; conhecimento profundo...; conhecimento científico...; ramo do conhecimento...; conhecimento sobre determinado assunto...; entendimento de como tudo acontece...; existe para... compreender...; conhecimento existente na terra...; conhecimento teórico e prático...; conhecimentos adquiridos...; conhecimento a respeito de um dado tema...; é toda forma de conhecimento...; é conhecimento...; abordagem que rege o conhecimento do mundo...; produção de conhecimento...; é a arte do conhecimento...; é todo conhecimento humano...; descobertas...; conhecimento com certeza...; ciência que revela...; níveis de conhecimento humano...; busca 
pelo saber...; pelo conhecimento...; encontre respostas...; aquisição de conhecimentos...; saber a verdade...; ramo do conhecimento...; conhecimento formado...; se descobre alguma coisa...; é um conhecimento...; é um corpo de conhecimentos...; desenvolver teorias...; conhecimento que pode ser...; conhecimento que possui garantia...; Comprovação empírica: que pode ser comprovado...; constatação empírica...; através da experimentação...; que possam ser provadas....; cientificamente provado...; experiência...; de certa forma empírica...; estudo sistemático...; aquilo que é comprovado...; aprovado por pesquisas...; cientificamente comprovado...; fatos relacionados...; ir além das observações...; tomando por base leis pré-determinadas...; com base em princípios...; procura explicar experimentalmente...; existir experimento...; como se processa...; dados são obtidos empiricamente...; tem de empírico...; estudo através da experimentação...; que pode ser provado...; legitimidade...;, Método/Metodologia: organizado... (2); preceitos técnicos...; é um método de estudo...; com a utilização de um método...; que tenham fundamento...; baseada em método científico...; utiliza uma variedade de método...; é um processo...; forma como é organizado...; método de estudo que tem fundamentação...; que pode ser comprovado...; é um dos métodos...; sistemático...; metodologia de estudo direcionada...; metodologia...; uma metodologia...; Investigação: Tudo aquilo que é investigado; se preocupa com a investigação...; investigação acerca de fenômenos...; Explicar: mostrar a realidade dos fatos...; elucidação de objetos e coisas...; ciência... que explica...; por quê dos fatos...; explicar a realidade...; explica através da teoria...; busca respostas... .

A CATEGORIA 2 - (PPS) refere-se à Percepção da Psicologia evocada pelo grupo, onde sobressaíram-se duas subcategorias: Ciência, com duas subcategorias: do Comportamento: ciência que estuda o comportamento do homem (8); ciência que estuda o desenvolvimento...(3); , e da Mente: ciência que estuda o psicológico...; ciência que estuda o comportamento da mente...; ciência que estuda a psique humana...; ciência que estuda a mente humana..; ciência... comportamento da mente...(3); ciência que desvenda e revela a mente...; ciência que estuda os processos mentais...;, e Estudo, com duas subcategorias: do Comportamento: estudo do comportamento humano...; estudo do comportamento...; estudo do comportamento humano e do seu desenvolvimento...; da Mente: estudo do comportamento da mente...; estudo... dos processos mentais...; ramo que assiste as patologias psico-humanas...; estudo da ciência do psicológico... .

A CATEGORIA 3 - (IPS), refere-se à Importância da Psicologia, onde sobressaíram-se seis subcategorias: Ajudar: auxiliar nas intervenções humanas...; auxiliar Acesso através do site: http://idonline.no.comunidades.net 
no processo de cada sujeito...; para auxiliar...; ajudar alguém...; ajudar a desenvolver e superar dificuldades...; ajudar...; ajudar o homem...(2); ajudar os seres humanos...; ajudar a entender...(2); ajudar as pessoas... (3); auxiliá-las nas descobertas...; ajudá-las nas patologias...; auxiliar o desenvolvimento humano...; ajudar os indivíduos...; auxiliar nos distúrbios...; .auxiliar as diversas áreas...; ajudar no crescimento...; ajudar a conhecer...; ajudar nos esclarecimentos...; ajudá-lo em determinadas...; atender os pacientes...; assistir as pessoas...; atender as pessoas que necessitam...; atender às necessidades...; melhorar a vida...; melhorar o convívio...; melhorar o nosso modo de viver...; influenciar as pessoas...; otimizando as relações sociais...; prometendo uma socialização; .colaborar com o ajustamento...; contribuindo para...;, Compreender: melhor compreender...; para compreender...; compreender algum distúrbio...; compreender... (2); tendem a compreender as atitudes humanas...; entender o pensamento e as ações...; entender como funciona a mente...; entender...; ajudar a entender...; ajudar no entendimento...; entender melhor a si $e$ aos animais...; entender melhor...; .entender determinado assuntos...; compreender o ser humano...; identificar manifestações...; explicar os fenômenos...; explicações do funcionamento...; Estudar: estudar o comportamento...(2); estudar e avaliar o homem...; para tratamento e estudos...; aprofundar estudos sobre o ser...; ...estudar os modos das pessoas agirem...; estudar o indivíduo...; estudar a mente...; .pesquisar...; .estudar as pessoas...; estudo do comportamento...; conhecer as atitudes humanas...; conhecer mais pessoas e seus comportamentos...; descobrir...; conhecer problemas...; conhecerem os outros...; aprofundar-se nesses estudos...; analisar comportamento.. (3); avaliar a relação do indivíduo...; buscar respostas...; aprender a cuidar...;, Resolver: resolver problemas...; tentar resolver...; superar seus problemas e transtornos...; solução dos seus problemas...; estudar o ser humano...; resolução de problemáticas..;; Auto-conhecimento: lidar consigo mesmo...; auto-definição...; compreender a si mesmo...(2); para o auto-conhecimento...; a se conhecerem...; conhecer sobre nós mesmos...; tenha conhecimento...; conhecimento do eu...;, Tratar: para tratamento...; tratar alguma patologia...; tratar distúrbios comportamentais...; acompanhar as pessoas com transtornos... .

A CATEGORIA 4 - (IPP), refere-se à Imagem do Papel do Psicólogo, onde sobressaíram-se seis subcategorias: Solucionar conflitos: resolver seus conflitos...; intervir nos problemas...; intervir nos problemas...; encontrar meios...; solucionar problemas da sociedade...;, Melhorar bem-estar: pessoas se sintam melhor...; ...mais relaxados quanto a problemas...; melhorar a qualidade de vida...; pessoas mais humanas...; conseguir uma harmonia...; tornar a sociedade melhor...; contribuir para o bem-estar...; aumentar a auto- 
estima...; tornar a sociedade mais harmônica...(2); proporcionando conforto...; sociedade de pessoas equilibradas...; harmonia do indivíduo consigo mesmo...; evitar... o estresse...;, Compreender: compreender...(2); compreendendo seu comportamento...; decifrar... os males mentais...; entender o comportamento...; conhecimento dos males humanos...; compreendê-la...;, Melhorar relacionamentos: melhorar os relacionamentos...; interagir com a comunidade...; melhorar o convívio social...; um bom relacionamento entre as pessoas...; educador da ordem social...; controlar o comportamento...; trabalhar questões de cidadania...; interagir...; mostrar a sociedade...; uma sociedade melhor...; sociedade menos problemática...; integrador social..; pessoas mais integradas...; uma relação melhor...; bom relacionamento entre elas...; agir num grupo social...; busca de harmonia...; entender...; fazer as pessoas.. .se conhecerem...;, Estudar: estudar o comportamento...; estudar métodos de tratamentos...; analisar pelo que a sociedade está passando...; analisar as várias...; sabido na área do pensamento...; Ajudar: orientador...(2); orientar as pessoas...; ajudar...(5); ajudar na busca de respostas...; ajudar a formar...; ajudar pessoas...(5); ajudar a combater os males...; auxiliar no desenvolvimento...; ajudar o ser humano...(2); ajudar a uma melhor integração...; auxiliar os estresses...; oferecer ajuda...; ajudar-nos a ter...; ajudar as pessoas...; auxiliar as pessoas...; ajudar na reflexão...; ajudar os indivíduos...; oferecer serviços...; conscientizar pessoas...; orientá-los...; incentivar...; cuidando da parte emocional...; conselheiro...; amenizar as patologias.... .

\section{Análise dos resultados e discussão}

Com relação à Concepção de Ciência, a pesquisa demonstrou uma percepção de ciência como estudo (28,2\%), Conhecimento (26,5\%), Comprovação empírica (15,4\%), Método/Metodologia (13,7\% ), Investigação(10,2\% ) e Explicar (6,0\%).

Observa-se que emerge uma concepção bastante ligada a um conceito de ciência como um conjunto de conhecimentos, derivados de estudos, posições e princípios - Estudo (28,2\%) e Conhecimento (26,5\%). Essa concepção parece relacionada com a concepção racionalista, que sugere ser a ciência uma unidade sistemática de axiomas, postulados e definições, que determinariam a natureza e as propriedades de seus objetos, de forma que se poderiam provar as relações de causalidade de um objeto investigado. Neste caso, a ciência é vista como um 
conhecimento racional dedutivo e demonstrativo, capaz de provar a verdade universal de seus enunciados e resultados, sem deixar dúvidas (CHAUÍ, 2000).

Também emergiu uma concepção de ciência que segue o sentido das ciências positivas, de laboratório, ligadas a comprovar através de um método - Comprovação empírica (15,4\%) e Método/Metodologia (13,7\%). Observa-se, neste caso, uma similaridade com a concepção empirista que, segundo Chauí (2000), afirma ser a ciência uma interpretação dos fatos baseada em observações e experimentos. Os experimentos elaborados com o rigor do método nos procedimentos permitiriam uma definição mais realista do objeto, das suas propriedades e das suas leis de funcionamento. Assim, uma teoria científica seria resultado de observações e experimentos.

No curso dos debates sobre a ciência, se parte do pressuposto de que fazer ciência é elaborar conhecimentos confiáveis ou verdadeiros sobre a realidade. Assim, uma forma válida de se conceber um conhecimento de qualidade seria através de uma comprovação empírica e com um método coerente com o objeto a ser estudado.

Emergiu ainda uma concepção de ciência mais relacionada a concepção construtivista que segundo Chaú (2000), considera a ciência uma construção de modelos explicativos para a realidade, através das evocações Investigação (10,2\% ) e Explicar (6,0\%). Neste caso, a ciência não objetivaria apresentar uma verdade absoluta à partir das observações e experimentos e sim uma verdade aproximada que pode ser corrigida, modificada ou abandonada por outra mais adequada.

A Percepção da Psicologia emergiu de forma bifurcada, através de duas Subcategorias: Ciência $\mathbf{( 6 9 , 3 \% )}$, por sua vez, com duas subcategorias - $\underline{\text { do comportamento }}$

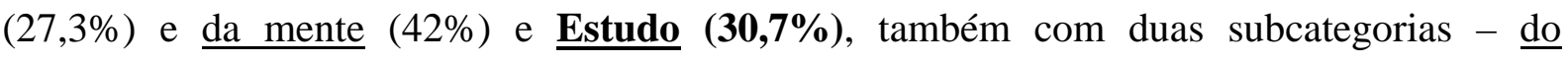
comportamento $(15,9 \%)$ e da mente $(14,8 \%)$.

Para que se possa entender uma área da ciência é preciso delimitá-la. No caso da psicologia, para que se tenha uma percepção mais próxima do seu propósito, faz-se necessário que antes haja uma compreensão do que é, para que serve, quais são seus objetos de investigação e conteúdos. Esta situação ficou evidenciada na prática, com relação à psicologia, onde os acadêmicos estudados se mostraram confusos quanto ao fato dessa ser 
uma Ciência ou um Estudo. Também observou-se desinformação quanto ao seu objeto de estudo, se seria a mente ou o comportamento.

Desde os anos vinte, a psicologia vem sendo a ciência do futuro. O avanço desta a partir da Segunda Guerra Mundial enfatizou a idéia que hoje segue presente entre professores e estudantes universitários. Trata-se de uma linha eminentemente clínica que tem se desenvolvido na Europa e em nosso país, baseada na resolução de problemas de conduta. Apesar da abertura de novas profissões ao alcance dos psicólogos, esta ainda se dá de maneira insuficiente. Sem dúvida um dos fatores que tem contribuído para isso é o escasso conhecimento que se tem desta ciência, da sua diversidade e da existência de outras necessidades sociais mais urgentes (DELGADO, 2005).

Na prática, muitas pessoas ainda percebem a psicologia diferente do que ela realmente é, uma área da ciência que usa a investigação experimental e metodologias adaptadas a seu objetivo de estudo do comportamento, tal como sugere Delgado (2005, p.01) em sua definição de psicologia "é o estudo do comportamento e da capacidade do ser humano para perceber, classificar e transformar a informação que recebe do meio ambiente e social”. Esta não pareceu ao autor citado, uma definição completa, uma vez que a psicologia, segundo ele, é um conjunto de técnicas que utilizamos com o propósito de estudar a conduta e, todo o método utilizado para se elaborar soluções a diferentes tipos de problemas.

Observou-se no nesse estudo que $42 \%$ dos sujeitos a perceberam como uma ciência da mente, talvez pela própria sugestão do nome "Psico" e "Logia”, termos gregos que significam mente e estudo, respectivamente. Também houve dúvida a respeito da psicologia se referir a um estudo do comportamento ou da mente.

Delgado (2005) sugere que uma nova maneira de se perceber a psicologia é entendê-la como o desenvolvimento de investigações e estudos acerca do comportamento e de como este realmente afeta as pessoas em todos os âmbitos e realidades. Seria uma forma de saber mais sobre nós mesmos e sobre os demais e, de como nos relacionamos conosco e com o nosso meio ambiente.

Álvaro (1995) acrescenta que a Psicologia é uma ciência que estuda o ser humano em suas diversas expressões e situações, nas dimensões cultural, histórica, social e biológica, tanto a nível individual, grupal, quanto institucional, realizando tal investigação através de 
ações sistemáticas. O autor nos informa que a psicologia vem acumulando um patrimônio de conhecimentos explicativos e aplicativos através de seu desenvolvimento metodológico e que, graças a esta acumulação de conhecimentos tem proposto diferentes concepções e teorias para explicar o comportamento social humano, de maneira a aproximar-se cada vez mais da realidade.

Quanto às representações sociais da Importância da Psicologia sobressaíram-se seis subcategorias: Ajudar (37,6\%); Estudar (24\%); Compreender (18,7\%); $\underline{\text { Auto-conhecimento }}$ (9,4\%); Resolver (6,2\%); e Tratar (4,1\%). A psicologia parece ter para os acadêmicos uma importância positiva. Algo que trás uma contribuição em forma de ajuda (ㅅjudar). Observa-se uma representação dessa importância também muito associada à prática clínica onde compreender, promover o auto-conhecimento, resolver problemas e tratar de dificuldades estariam vinculados às atribuições do profissional da Psicologia.

Observa-se cada vez mais que a religião, a fé, as profecias tomam conta da atenção das pessoas em detrimento dos estudos psicológicos. É cada vez maior o número de profetas, de religiões que pregam uma conexão "correta" com a divindade, de maneira tão envolvente, a ponto de distanciar os indivíduos das suas reflexões pessoais, psicológicas e de seus próprios sentimentos diante do mundo. A Psicologia hoje parece concorrer com charlatões, profetas, discípulos, cartomantes, numerólogos. O trabalho do Psicólogo tende a ser cada vez menos compreendido na sua real importância.

Em grande parte das vezes a solicitação do trabalho do Psicólogo é desprezada, por estar em tentativa de disputar com esses conhecimentos outrora citados. É preciso que a psicologia possa cada vez mais e através de estudos sistemáticos, propor formas alternativas de mudança social embasadas em um criterioso estudo científico.

É possível que uma das explicações para isto esteja no fato de que, estamos vivendo um momento no mundo em que cada vez mais o sujeito, as pessoas, vêm perdendo seu contato com o outro. A relação entre as pessoas seja relação amorosa, sexual, religiosa, vem sendo suprimida em prol de uma constante relação narcísica. Uma sociedade individualista, onde "é cada um por si" (BARRA, 2005). Esta situação agravada por novos meios de comunicação de massa, implicaria numa exacerbação de relações cada vez mais pobres do ponto de vista existencial. Refletir sobre essa configuração social é ter a possibilidade de questioná-la, mudá-la. 
A diversidade de informações, escolas e teorias psicológicas cria um vasto campo de conhecimentos e, mesmo que não seja possível abarcá-los de todo, é necessário conhecê-los, no mínimo, em parte (JUREMA et al., 2005).

É inegável a contribuição da psicologia nos diversos seguimentos humanos e sociais. Através de suas teorias, a Psicologia passa a desempenhar o seu papel primordial que é o de ajudar a aprimorar as atividades realizadas por pessoas ou grupos de pessoas, bem como auxiliar na resolução de problemas que envolvam relacionamentos. A importância da participação da Psicologia, como área investigativa, se dá também quando se tenta conhecer a personalidade, o contexto sócio-laboral, as necessidades individuais e coletivas, a inteligência, as emoções, a memória, a percepção, bem como geração de Bem-estar e saúde mental.

A Importância da Psicologia, emerge com significados mais coerentes com a prática clínica, tais como ajudar (37,6\%); estudar (24\%); compreender (18,7\%); autoconhecimento (9,4\%); resolver (6,2\%); e tratar (4,1\%). A psicologia parece ter para os acadêmicos uma importância positiva.

Quanto às representações sociais da Imagem do Papel do Psicólogo, sobressaíram-se seis subcategorias: Ajudar (41,3\%); Melhorar Relacionamentos (22,3\%); Melhorar Bemestar (16,4\%); Compreender (8,2\%); Estudar (5,9\%); e Solucionar Conflitos (5,9\%). Observou-se uma percepção favorável relativamente à imagem do Papel do Psicólogo, Como aquele que ajuda, que melhora relacionamentos, que melhora o bem-estar, que compreende, estuda e soluciona conflitos. Uma imagem que parece baseada numa imagem do psicólogo como um agente capaz de oferecer ajuda em momentos de dificuldade, não propriamente um solucionador de problemas, mais evidenciada numa visão de prática clínica. Esta imagem está de acordo com o pensamento de Baró (1997), que acredita ser trabalho profissional do psicólogo definido em função das circunstâncias concretas da população a que deve atender. O autor enfatiza que, ainda que o psicólogo não seja chamado para resolver problemas, ele deve contribuir, a partir de sua especificidade, para buscar uma resposta, isto é, ele deve ajudar as pessoas a superarem sua identidade, pessoal e social, ao transformar as condições difíceis do seu contexto.

Observou-se também que a imagem do Papel do Psicólogo entre esses sujeitos emerge de forma favorável, uma vez que o mesmo é visto como uma pessoa capaz de ajudar (41,3\%), de melhorar relacionamentos (22,3\%), melhorar bem-estar (16,4\%), compreender (8,2\%); estudar (5,9\%); e solucionar conflitos (5,9\%). A imagem de um 
agente capaz de oferecer ajuda em momentos de dificuldade, não propriamente um solucionador de problemas.

O estudo demonstrou que entre os universitários há uma certa compreensão relativamente a Importância da Psicologia e a Imagem do Papel do Psicólogo, porém quando se trata da Percepção da Psicologia, esta parece confusa quanto ao fato de ser uma Ciência ou campo de Estudo e, ainda se seu objeto é a mente ou o comportamento. Os resultados nos levam a crer que esta situação acontece por conta dos acadêmicos, objetos deste estudo, ainda conservarem uma Concepção racionalista de Ciência, em detrimento de uma concepção construtivista, o que estaria mais de acordo com a própria natureza humana. O estudo também demonstrou a necessidade de uma maior compreensão do conceito de Psicologia e de seu objeto de estudo entre os sujeitos.

\section{Referências}

ABRIC, J. C. A abordagem estrutural das representações sociais. In: MOREIRA, A. S. P.; Oliveira, C. C. (Orgs.). Estudos interdisciplinares de representação social. Goiânia: AB, 1998.

ÁlVARO, J. L. Psicología Social: perspectivas teóricas y metodológicas. Madrid, Siglo XXI, 1995.

BARDIN, L. Análise de conteúdo. 70 ed. Lisboa: edições 70, 1991.

BARRA, A. (2005). A importância da psicologia na sociedade. Disponível em: http://www.capsiucg.hpg.ig.com.br/art1.htm. Acesso em: 13 mai. 2005.

BARÓ, I. M. O papel do psicólogo. Estudos de Psicologia, Natal, v. 2, n. 1, p. 7-27, jun. 1997.

BERELSON, B. Content analysis in communications research. Glencoe: Free Press, 1952.

BUENO, G. Que és ciência? La respuesta de la teoria del cierre categorial. Ciência y Filosofia. Oviedo: Pentalfa Ediciones, 1995.

CHAUI, M. Convite à filosofia. São Paulo: Ática, 2000.

COUTINHO, M. da P. de L. Depressão infantil: uma abordagem psicossocial. João Pessoa: Editora Universitária, 2001.

DELGADO, M. G. (2005). Um Nuevo concepto de psicologia. Disponível em: http://www.psicodelgado.com/nuevo\%20concepto.htm. Acesso em: 12 mai. 2005. 
JUREMA, A. et al. (2005). A importância da psicologia da educação. Disponível em: http://www.educacaoglobal.hpg.ig.com.br/psicologia_da_educacao/importancia_psicolo gia.htm. Acesso em: 10 mai. 2005.

KHUN, T. A Estrutura das Revoluções Científicas. São Paulo: Editora Perspectiva, 1976.

KRIPPENDORFF, K. Content Analysis: an introduction to its methodology. Newbury Park, CA: Sage, 1980.

MAGEE, B. As idéias de Popper. São Paulo: Cultrix,1979.

MESQUITA FILHO, A. (2005). Teoria sobre o método científico: em busca de um modelo unificante para as ciências e de um retorno à universidade criativa. Disponível em: http://www.ecientificocultural.com/ECC2/artigos/metcien1.htm. Acesso em: 08 mai. 2005.

MOSCOVICI, S. La psychanalyse son image et son public. Paris: Presses Universitaires de France, 1961.

A representação social na psicanálise. (Trad. Álvaro Cabral). Rio de Janeiro: Zahar, 1978.

. Psycologie Sociale. Paris: Press Universitaire de France/PUF, 1984.

POPPER, K. Conjectures and refutations. London: Routledge, 1963.

A lógica da pesquisa científica. 9 ed. São Paulo: Cultrix, 1993.

RODRÍGUEZ, A. Aplicações da Psicologia Social. Petrópolis: Editora Vozes, 1981.

RODRÍGUEZ, C. M. (2005). Filosofia de la ciência. Disponível em: http://www.enciclopedia.us.es/index.php/Filosof\%EDa_de_la_ciencia.htm. Acesso em: 13 mai. 2005.

VALA, J. A análise de conteúdo. In: SILVA, A. S.; PINTO, J. M. (Orgs.). Metodologia das ciências sociais. Porto: Edições Afrontamento, 1986. p. 271. 